Volume 11

Issue 1 Winter 2018

Article 14

2018

\title{
Parts of the Whole: Hands On Statistics
}

\section{Dorothy Wallace}

Dartmouth College, dorothy.wallace@dartmouth.edu

Follow this and additional works at: https://digitalcommons.usf.edu/numeracy

Part of the Higher Education Commons, and the Science and Mathematics Education Commons

\section{Recommended Citation}

Wallace, Dorothy. "Parts of the Whole: Hands On Statistics." Numeracy 11, Iss. 1 (2018): Article 14. DOI: https://doi.org/10.5038/1936-4660.11.1.14 


\title{
Parts of the Whole: Hands On Statistics
}

\author{
Abstract \\ In this column we describe a hands-on data collection lab for an introductory statistics course. The \\ exercise elicits issues of normality, sampling, and sample mean comparisons. Based on volcanology \\ models of tephra dispersion, this lab leads students to question the accuracy of some assumptions made \\ in the model, particularly regarding the normality of the dispersal of tephra of identical size in a given \\ atmospheric layer.

\section{Keywords} \\ mathematics education, numeracy, statistics education, laboratory exercise \\ Creative Commons License

$$
\text { (c) (1) (8) }
$$ \\ This work is licensed under a Creative Commons Attribution-Noncommercial 4.0 License

\section{Cover Page Footnote} \\ Dorothy Wallace received her B.S. in mathematics at Yale University and her Ph.D. at the University of \\ California at San Diego, and is currently professor of mathematics at Dartmouth. She has broad \\ background in many kinds of mathematics, with approximately 100 publications in pure, applied, and \\ educational topics. From 1995 to 2000 she led the seminal Mathematics Across the Curriculum project \\ funded by the National Science Foundation. She was 2000 New Hampshire CASE Professor of the Year \\ and won the Dartmouth Graduate Faculty Mentoring Award in 2005. In the last 9 years she has supervised \\ 45 undergraduates conducting research through internships, independent study, and senior theses. Her \\ research papers in mathematical biology include 29 undergraduates among her coauthors. She was a \\ charter board member of the National Numeracy Network and is a founding co-editor of this journal.
}




\title{
Parts of the Whole
}

\author{
A Column by D. Wallace
}

The problem of how best to improve the numeracy of a society is a thorny one, embracing the learning process of a single student but rising in scale to include the management and alteration of an entire system of education. With the issue of quantitative literacy always in mind, this column will consider various aspects of the systemic workings of education: the forces acting on classrooms, teachers, and students and mechanisms of both stasis and change. With the issues of volume 9, the column has pivoted to thoughts from developing and teaching "Math 4: Applications of Calculus to Mathematics and Biology," which Dartmouth biology students can take as an alternative to second-semester calculus (see Rheinlander and Wallace 2011).

\section{Hands On Statistics}

Active learning can take many forms, including classroom discussion, analyzing data sets, development of projects, and in the case of introductory statistics, data collection. For a few years I have worked on revising the introductory statistics courses offered by my department, with an eye to making each class at least fifty percent "lab." By this I mean that half of classroom time would be devoted to investigating data sets and answering relevant questions about them. Such investigations are the very point of using statistics at all.

There are a few problems with such an approach. First of all, data collection itself is an expensive and questionable use of students' class time. It has to be done in a pointed manner that makes it clear why it is worth the effort. The literature is full of descriptions of data that have already been gathered, and often some statistical tests have already been done on those data. Unless the specific goal of a given lesson is for students to learn how to upload and manage a data set using a particular software, there is barely a need to deal directly with a large data set. Sometimes there is a good reason to look at the data directly, often because they already exist and it is not necessary or even possible for students to collect their own.

It is easy to collect a lot of data: student's heights, the width of the textbook, endless rolls of a die, etc. This obvious fact brings us to the second problem with data collection: who cares? Figuring out how to make such data interesting is a challenge. I find if I have students spend ten minutes collecting this sort of data, they don't mind. More than ten minutes leads to a sense of pointless activity. Active learning is great, but pointlessly active non-learning is not great. 
Third, the goal of readying students to read technical literature should be part of every statistics course, and it is hard to integrate that goal with a data collection exercise. In this column I will describe a classroom (actually outdoor) activity designed to address all three of these problems: being worth the time, answering an interesting question, and having a connection to the literature.

\section{Questioning Authority Again Today}

The source of inspiration for this exercise was a conversation with some geology graduate students working with Dr. Chuck Connor at the University of South Florida. Connor's research includes the reconstruction of parameters associated with volcano explosions (e.g., Connor 2011; Courtland et al. 2012; Connor and Vacher 2016). One small aspect of the problem is using a model to conclude that diffusion of tephra particles, in the absence of wind, results in a normal distribution of the concentration of particles of a given size at a given height in the atmosphere (Bonadonna et al. 2005).

I asked the graduate students if they had any physical evidence confirming that this distribution would actually occur - that lots of identical small objects shot upwards into the atmosphere would, upon falling, be normally distributed. The students admitted that they had no lab simulation confirming this model. I asked them directly why they believed it. Perhaps they would give a passionate defense of the diffusion equation. No, they believed it because their advisor had asserted it.

They also discussed ways of testing it, using perhaps a small canon in an empty lot.

Thanks to those discussions, a statistics lab was born. Thanks to a demonstration and directions on YouTube, a candy canon was built (Candy Canon 2012).

\section{Interesting Research Questions}

Because activities of this sort take up time, an instructor wants to get as much math out of the event as possible. Given a distribution of data (candy in this case), can we reconstruct where the explosion took place? How accurate will that be? Will the data really be normally distributed? Can we have teams of students take random samples of the data so that we can compare sample means and see confidence intervals in action? A data collection activity that could address all of these questions at once would be worth the time spent on it.

The canon, constructed according to the directions on Youtube (Candy Canon 2012), was able to propel about 300 pieces of paper-wrapped Jolly Rancher fruit chews over 15 feet from its location. The candy came in eight different colors, 
providing eight random samples for eight groups of students. The patio outside the math department was conveniently gridded in three-foot squares. The coordinate axis was labeled. Before the students could see it, the canon was placed on the grid and its true coordinates were recorded. After the explosion, students came out, armed with yardsticks, to measure the location of their groups' data points (Fig. 1).

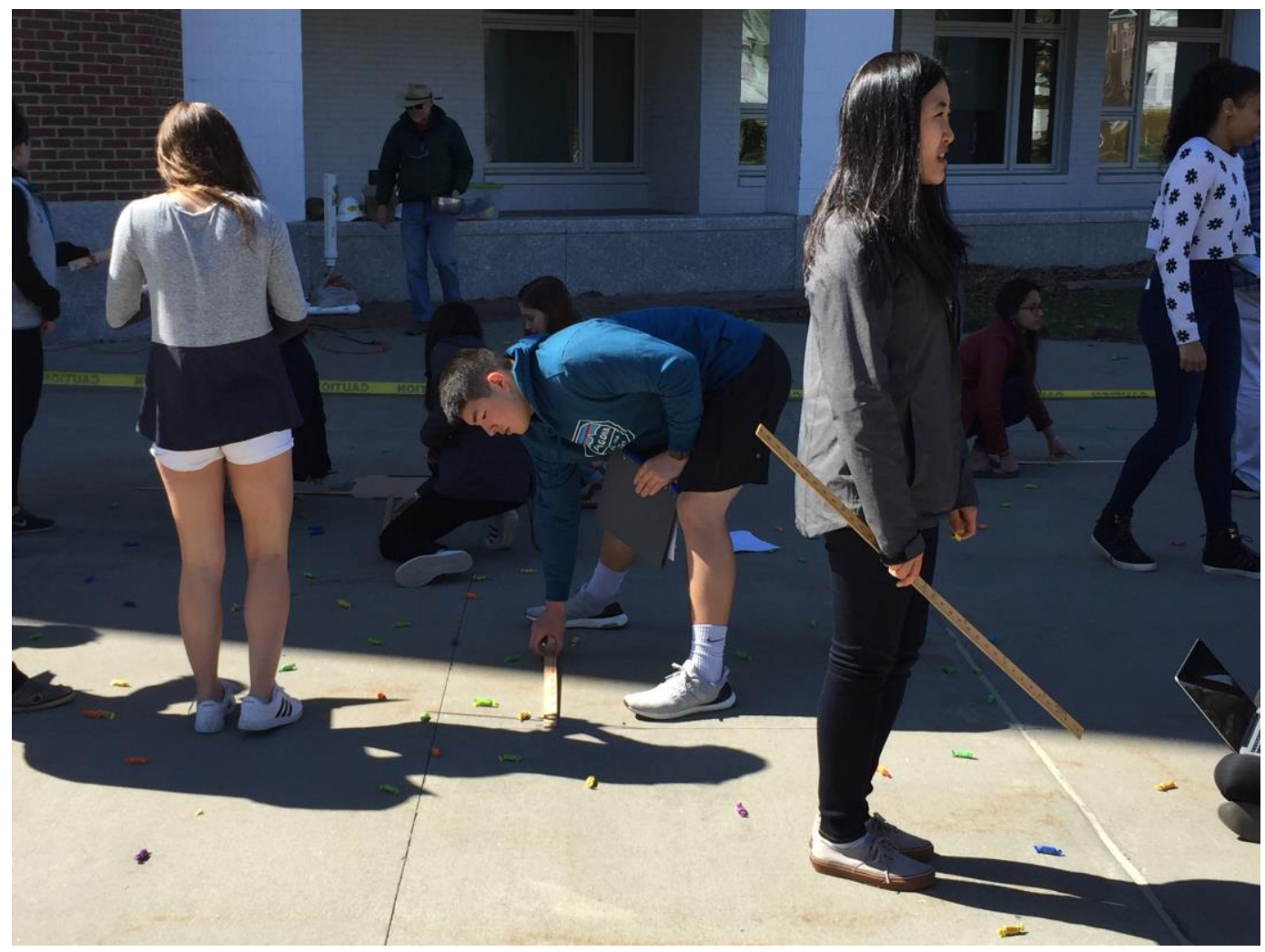

Figure 1. Students engaged in data collection. Teams collect candy of their assigned color. One measures, one runs, one records. The candy canon is visible in the back, with the operator next to it. follows:

According to the notes from my lesson plan, the activity was introduced as

"We need some data to analyze using the full power of the central limit theorem and it needs to be a random sample, often difficult to arrange. I have arranged one for you. Data collection, Boom!"

After collecting all the data, the data "points" were returned to the canon for a second explosion because students were not allowed to see the first explosion. Then groups collected their data again according to color, and during the subsequent class time they ate the data. 


\section{Analyzing Our Own Data}

The first order of business after data collection was to double check the spreadsheets and email all of them to me. Then each team computed the mean, standard deviation and standard error for both the $x$ - and $y$-coordinates of their data points.

At this point the idea of a confidence interval was introduced, and students used their samples to estimate the population mean within a $95 \%$ confidence interval. These values were all put on the board in order to observe the overlap between them, the different sizes of confidence interval, and so forth. Because the standard deviation of the population is not known, it became necessary to think about Student's $t$-test and recompute the confidence intervals.

We then moved on to the notion of a null hypothesis, asking whether it appeared that blue candy was distributed differently from red candy. This question led to a discussion of the difference between two means and its associated standard error. A discussion of the interpretation of standard error in this context returned us to the observation that all of statistics proceeds by a metaphor with probability, and all statistical tests "work" because of random sampling.

One of the original questions we were investigating was whether volcano tephra ought to be normally distributed. To this end, I compiled all of the data sets and returned them to the students. The question of whether they were normally distributed became an essay question to be completed in advance of the midterm. The instructions read:

\footnotetext{
"Hi Math 10! Along with this document you are receiving an Excel spreadsheet with ALL of the data for the candy explosion. Not everyone reported it the same way on their spreadsheet so you will have to make it consistent. Your job is to use the full force of Excel and your best brainpower to answer this question:

Is the data ( $x$ coordinate, $y$ coordinate, distance from "center") normally distributed?

Please turn in ONE page of neatly typed and carefully proofread beautiful prose explaining your conclusion. You may, and should, include graphics that make your point. You must include summary data as needed. Don't forget to put your name on it. More points will be given for more thoughtful approaches, more methods tested, etc. This problem is worth $25 \%$ of your midterm.

A related question that makes me wonder: Why is it that two groups described their candy color as "dark green" and one group as "light green"? You don't have to answer this."
}

The answer to that last question turned out to be that one group did not turn in their data at all and the "dark green" group turned it in twice. The second error was corrected. The consensus of the class was that the group that did not turn in 
their data had realized that they did not follow directions and had measured incorrectly.

\section{Conclusion}

The fake volcano activity succeeded on several fronts. The students did not find it boring. One actually exclaimed, "This is fun!" Whether it was the connection to a serious research question, the fine spring day, or the sugar rush, I cannot say. Probably all of these helped.

The data had enough going on in it to sustain discussions on multiple topics. We could talk about the normal distribution, sample means, confidence intervals, and differences between means, all with respect to this data set. We pondered the importance and difficulty of obtaining a random sample. Data collection takes up precious time but we got enough out of this data set to make it worth it.

By now the reader should wonder, what was the answer? Was the distribution in fact normal? There are many tests for normality. Students graphed histograms. They compared the mean and median. They counted the number of data points within one standard deviation. They looked up additional methods of determining normalcy and computed away. How close to normal is "normal enough"? That was the question.

And, as with the famous story of the lady and the tiger (Stockton 1884), the answer was inconclusive.

\section{References}

Bonadonna, C., C. B. Connor, B. F. Houghton, L. Connor, M. Byrne, A. Laing, A. and T. K. Hincks. 2005. "Probabilistic Modeling of Tephra Dispersal: Hazard Assessment of a Multiphase Rhyolitic Eruption at Tarawera, New Zealand." Journal of Geophysical Research: Solid Earth: 110 (B03203). https://doi.org/10.1029/2003JB002896

Candy Canon, 2012. https://www.youtube.com/watch?v=VgZhQJQnnqA

Connor, C. B. 2011. "A Quantitative Literacy View of Natural Disasters and Nuclear Facilities." Numeracy 4 (2): Article 2. https://doi.org/10.5038/1936-4660.4.2.2

and H. L. Vacher. 2016. "Learning Volcanology: Modules to Facilitate Problem Solving by Undergraduate Volcanology Students." Statistics in Volcanology: Vol. 2: Article 3. https://doi.org/10.5038/2163-338X.2.3

Courtland, L. M., C. Connor, L. Connor, and C. Bonadonna. 2012. "Introducing Geoscience Students to Numerical Modeling of Volcanic Hazards: The example of Tephra2 on VHub.org." Numeracy 5 (2): Article 6. https://doi.org/10.5038/1936$\underline{4660.5 .2 .6}$

Stockton, F. R. 1884. The Lady, or The Tiger, and Other Stories. Edinburgh, David Douglas, Castle Street, available at: https://archive.org/stream/ladyortigerandot00stociala\#page/n5/mode/2up 